\title{
Use of Vildagliptin in Management of Type 2 Diabetes: Effectiveness, Treatment Persistence and Safety from the 2-Year Real-Life VILDA Study
}

Dominique Simon • Bruno Detournay $\cdot$ Evelyne Eschwege $\cdot$

Stephane Bouée $\cdot$ Jacques Bringer $\cdot$ Claude Attali $\cdot$ Sylvie Dejager

To view enhanced content go to www.diabetestherapy-open.com

Received: February 17, 2014 / Published online: April 12, 2014

(C) The Author(s) 2014. This article is published with open access at Springerlink.com

\section{ABSTRACT}

Introduction: There is an increasing interest for real-life data on drug use in many countries. Reimbursement authorities more and more request observational studies to assess the conditions of use of the products but also to

Electronic supplementary material The online version of this article (doi:10.1007/s13300-014-0064-0) contains supplementary material, which is available to authorized users.

D. Simon

Diabetes Department, Pitié-Salpétrière Hospital, and Pierre et Marie Curie University, Paris, France

B. Detournay · S. Bouée

CEMKA-EVAL, Bourg-La-Reine, France

E. Eschwege

INSERM U-1018, Centre de Recherche en

Epidemiologie et Santes des Populations (CESP),

Villejuif, France

J. Bringer

Department of Endocrinology-Metabolism and

Diabetology, Lapeyronie Hospital, Montpellier,

France

C. Attali

Medical Group Practice, Epinay Sous Sénart, France

\section{S. Dejager $(\bowtie)$}

Clinical Affairs, Novartis Pharma SAS, 10 rue Lionel Terray, 92506 Rueil Malmaison, France

e-mail: sylvie.dejager@novartis.com improve knowledge about efficacy and safety in the real world and on a longer term than in clinical trials.

Aim: To evaluate the effectiveness, treatment persistence and tolerability of vildagliptin in clinical practice.

Methods: This observational, 2-year prospective cohort study was conducted in France on request of the Health Authorities [Haute Autorite de Sante (HAS)]. Type 2 diabetic mellitus (T2DM) patients initiating vildagliptin (including the fixed combination vildagliptinmetformin) or treated for $<6$ months were recruited through a national representative sample of general practitioners (GPs) $(n=482)$ and diabetologists $(n=84)$ between March 2010 and December 2011. At inclusion and each follow-up visit at $\sim 6,12,18$ and 24 months, a questionnaire was completed by the physician collecting information on socio-demographic, clinical and biological data, treatments and adverse events.

Results: 1,700 patients were included: $60 \%$ were males, aged $63 \pm 11$ years, with diabetes duration $7 \pm 6$ years and body mass index (BMI) $30 \pm 6 \mathrm{~kg} / \mathrm{m}^{2} .45 \%$ were obese, $70 \%$ treated for hypertension and $66 \%$ for dyslipidemia. $64 \%$ of 
the patients received vildagliptin in dual therapy with metformin. $82 \%$ of patients completed the 2-year follow-up. Glycosylated hemoglobin $\left(\mathrm{HbA}_{1 \mathrm{c}}\right)$ decreased from a mean baseline of $7.8 \pm 1.2 \%$ when vildagliptin was started, to $7.0 \pm 1.1 \%$ at 6 months and remained stable thereafter over 2 years. Mean weight, glomerular filtration rate, liver enzymes, and lipid parameters were unchanged over the study period. Eight patients $(0.5 \%)$, all concomitantly treated with insulin and/or sulphonylureas, reported one severe hypoglycemia and 47 (2.9\%) patients reported 64 non-severe symptomatic hypoglycemia (59\% occurred when patients were treated with insulin and/or sulphonylureas). At 6 months, $44.9 \%$ of vildagliptin-treated patients reached an $\mathrm{HbA}_{1 \mathrm{c}}$ $<7 \%$ without hypoglycemia and no weight gain, and this percentage increased to $49.7 \%$ at 24 months. Vildagliptin treatment maintenance at 2 years was $88.8 \%$ [95\% CI $(87.2 \%$; 90.4\%)], with $4 \%$ of patients discontinuing for adverse events.

Conclusions: In everyday conditions of care, vildagliptin efficacy was in line with existing data from randomized clinical trials, sustained over 2 years, with low discontinuation rate and low hypoglycemia risk.

Keywords: Diabetes;

Effectiveness; Endocrinology; HAS-requested study; Hypoglycemia; Observational; Type 2 diabetes mellitus; Vildagliptin

\section{INTRODUCTION}

The prevalence of type 2 diabetes mellitus (T2DM) is dramatically rising across the world, largely fueled by the epidemic of obesity and aging of the population [1]. The International
Diabetes Federation (IDF) estimates that 382 million people have diabetes in 2013 and this will rise to 592 million by 2035 [2]. In the USA, $8.3 \%$ of the population has T2DM [3], close to the overall latest 2013-IDF estimated prevalence of $8.5 \%$ in Europe [4]. In France, diabetes affects $4-5 \%$ of the adult population [5]. Prevention and treatment of the disease and its complications pose a major burden on national healthcare systems worldwide, accounting for $12 \%$ globally of the health expenditures in 2010 [6] and thus constitute one of the most challenging global health issues of the twenty-first century.

In addition to lifestyle changes, effective and safe pharmacological therapies are needed to manage T2DM. Several new classes of antidiabetic agents have recently been introduced in the management of T2DM. The 2012 position statement of the American Diabetes Association (ADA) and the European Association for the Study of Diabetes (EASD) reviews advantages and disadvantages of all available classes and proposes a patientcentered approach, taking into account patient preferences, effects on body weight and on hypoglycemia risk, cost and potential side effects of each class [7]. The latest 2013 HASFrench guidelines, however, recommend a more prescriptive algorithm with sequential choices essentially guided by long experience with the drugs and economic considerations [8].

Vildagliptin is a member of the new class of dipeptidyl peptidase 4 (DPP4) inhibitors that work by maintaining high levels of endogenous incretins. This leads to improved sensitivity of $\alpha$ - and $\beta$-cells to glucose, which results in glucose-sensitive modulation of insulin and glucagon secretion [9]. Vildagliptin has been shown to improve both fasting and postprandial glycemic control in T2DM patients [10] with a low risk of hypoglycemia 
[11], and is effective across a wide disease spectrum, from newly diagnosed patients [12, 13] to patients with long-standing T2DM [1417]. Indeed, the overall magnitude of glycosylated hemoglobin $\left(\mathrm{HbA}_{1 \mathrm{c}}\right)$ reduction has been found to be more or less similar throughout treatment stages, when used in monotherapy [18], in combination with one $[10,19,20]$ or two oral antidiabetic drugs (OADs) [21] or with insulin [22]. A hypoglycemia risk similar to placebo has consistently been seen with vildagliptin [11] including in high-risk patients such as elderly patients [23-25], patients with renal impairment (RI) [27-29] and/or patients treated with insulin $[14,30]$.

While the drug has been extensively studied in multiple randomized clinical trials (RCTs), additional data from large, non-selected patient populations in the real-world environment are valuable complements, which may be more applicable to daily management of T2DM [31].

In the present observational study, the authors have set out to evaluate the effectiveness, treatment persistence and tolerability of vildagliptin over 2 years following real-life prescription to patients with T2DM.

\section{METHODS}

\section{Study Design}

The VILDA study was a prospective, multicenter, observational study with a 2-year follow-up of patients with T2DM treated with vildagliptin (including the fixed combination of vildagliptin + metformin) under real-life conditions in mainland France. It was requested by French Health Authorities [Haute Autorité de Santé (HAS)] which reviewed and approved the study design and protocol. The objectives were to describe the characteristics of patients treated with vildagliptin and the conditions of use of the product, the maintenance rate and the frequency of/and reasons for treatment discontinuation, as well as to confirm the efficacy/safety profile (specifically the changes over time in $\mathrm{HbA}_{1 \mathrm{c}}$ and weight and the incidence of hypoglycemia over 2 years) under routine clinical care. In 2009, the indications listed in the vildagliptin Summary of Product Characteristics (SPC) were the use in dual therapy (as add-on to metformin, sulfonylureas or a thiazolidinedione if glycemic control was not obtained under monotherapy), while in 2012 additional indications for use as monotherapy, triple therapy or in combination with insulin had been added to the SPC.

The study was conducted by general practitioners (GPs) and specialists in endocrinology, diabetology and metabolic diseases (SPE) treating diabetic patients. 41,000 GPs were randomly drawn from a national database of all GPs practicing in France in 2009 and invited to participate by mail; 1,125 (2.7\%) agreed to participate and 483 included at least one patient. From all 1,878 diabetologists practicing in France in 2009, 187 (10\%) agreed to participate and 84 included at least one patient. Each participating physician had to include consecutively 1-5 patients. The physicians were free to treat and follow-up their patients as they saw fit, with no alteration in the physician-patient relationship, T2DM management and monitoring. During the period of inclusion, investigators had to complete a registry of noninclusion with the characteristics of patients who attended a consultation during the inclusion period and were eligible but were not included in the VILDA study, and the 
reasons for non-inclusion. Patients were recruited between March 2010 and December 2011.

\section{Patients}

All adult patients with T2DM spontaneously visiting a study physician (independently of the study), who had already started vildagliptin within the past 6 months or were about to start treatment with vildagliptin on the visit day, and who had agreed to participate in this study, were eligible for inclusion. Patients included in an interventional clinical trial or who had participated in one in the last 3 months, and those presenting a substantial risk of not being followed-up for 2 years (moving house, emigration, etc.) were not included in the study.

\section{Assessments}

At inclusion and each follow-up routine visit at approximately 6, 12, 18 and 24 months, a questionnaire was completed by the physician collecting information on socio-demographic, clinical (disease history, comorbidities, diabetes complications, concomitant therapies and lifestyle measures) and available biological data (no test was required by the protocol in this observational study), anti-diabetic treatments and adverse events (AEs). Micro and macro-vascular complications data were those declared by the investigators (no definition was provided in the protocol or cross-checking with collected biological data). Patient satisfaction with anti-diabetic treatment was measured using the Diabetes Treatment Satisfaction Questionnaire status version (DTSQs prior to vildagliptin initiation) and the Diabetes Treatment Satisfaction Questionnaire change version (DTSQc) [32] subsequently, to measure satisfaction in relation to the change in therapeutic strategy. The overall DTSQs score is interpreted such that the higher the score, the greater the satisfaction (with a maximum at 36). The total DTSQc score ranges from -18 to +18 . Outcome measures were those requested by HAS, namely the conditions of use of the product (proportion of patients who comply with the indications and precautions for use listed in the SPC); treatment maintenance rate over 2 years with frequency of/and reasons for treatment discontinuation; changes from baseline up to 2 years in $\mathrm{HbA}_{1 \mathrm{c}}$ levels (with both measurements performed at the same local laboratory using a Diabetes Control and Complications Trial reference method), and in body weight; the rate of hypoglycemia over 2 years, including all symptomatic hypoglycemia (with adrenergic and/or neuroglycopenic symptoms corrected after glucose administration) and severe hypoglycemia (requiring assistance of another person, coma, hospitalization). The proportion of patients for whom "therapeutic success" was met (defined as reaching an $\mathrm{HbA}_{1 \mathrm{c}}<7 \%$ without a single episode of hypoglycemia and without weight gain greater than $5 \%$ of baseline) was analyzed at 6, 12 and 24 months of treatment. Available biological data were collected at each visit (in addition to fasting plasma glucose and $\mathrm{HbA}_{1 \mathrm{c}}$ levels). They included creatinine levels and estimated glomerular filtration rate (eGFR) calculated using the Modification of Diet in Renal Disease (MDRD) formula [33], transaminase levels and all lipid parameters.

All AEs and serious AEs (SAEs) together with their severity and relationship to the study treatment were documented at each visit and analyzed in the whole population recruited in the study. 


\section{Statistical Analyses}

Quantitative or continuous variables were described by mean and standard deviation (SD) and in some cases median and range. Qualitative variables were described by absolute frequency and percentage per modality. Quantitative variables were compared between groups by Student tests in case of normal distribution and Wilcoxon-Mann-Whitney test otherwise. Qualitative variables were compared between groups using the Pearson Chi-square test if all theoretical sample sizes were $\geq 5$ or using the Fisher test if $<5$. All tests were performed with a significance level of 5\%. All statistical analyses were performed using SAS 9.2 software (SAS Institute, Cary, NC, USA).

To verify the representativeness of the physicians participating in the study, their characteristics were compared to those of all French physicians (age, gender, type and place of work). This analysis was performed separately for the GPs and for the endocrinologists. Representativeness of the patients included in the study was checked by a comparison with patients of the non-inclusion registry, a comparison of patients whose treatment began in the $<6$ months prior to the inclusion date with patients included on the day of vildagliptin initiation, and a comparison of patients who did not complete the study with those followed-up throughout the entire study period over the four planned visits.

Patient data were analyzed separately according to physician specialty (general or specialist practitioners) and pooled without weighting the sample.

Sample size was set to guarantee sufficient accuracy of the proportion of patients meeting the conditions of use of vildagliptin (estimated at $50 \%$ ). A cohort of 1,000 patients allowed to estimate this proportion with a precision of about $3 \%$ at a confidence level of $95 \%$; to take into account an expected $\sim 20 \%$ drop-out rate over 2 years, the sample size was thus set at 1,300 patients needed to be included in the study.

\section{Compliance with Ethics}

All procedures followed were in accordance with the ethical standards of the French Order of Physicians and Good Practices for Epidemiological Studies and with the Helsinki Declaration of 1975, as revised in 2000 and 2008. Candidates for inclusion were provided with full written information about the study. All data processing was carried out in compliance with French Information Technology and Privacy Law.

\section{RESULTS}

\section{Patient's Flow Chart and Baseline Characteristics}

A total of 1,763 patients were enrolled in the study, 1,700 were kept in the initial analysis and 1,639 in the follow-up analysis (see Fig. 1 for patients' flow chart). The mean follow-up period was 22.9 months, with $80.6 \%$ of patients followed for $\geq 22$ months.

Of the 1,700 patients, $26 \%$ were treated with vildagliptin and $74 \%$ with the fixed vildagliptin-metformin combination. $37.8 \%$ of patients had started vildagliptin within the previous 6 months and $62.2 \%$ started vildagliptin on the day of inclusion.

Of the 567 investigators (483 GP and 84 SPE) who included at least one patient, 392 (337 GP and 55 SPE) returned the registry of noninclusion ( $n=1,457$ patients). The comparison between these 1,457 patients with those included in the study did not identify any potential selection bias, though patients 


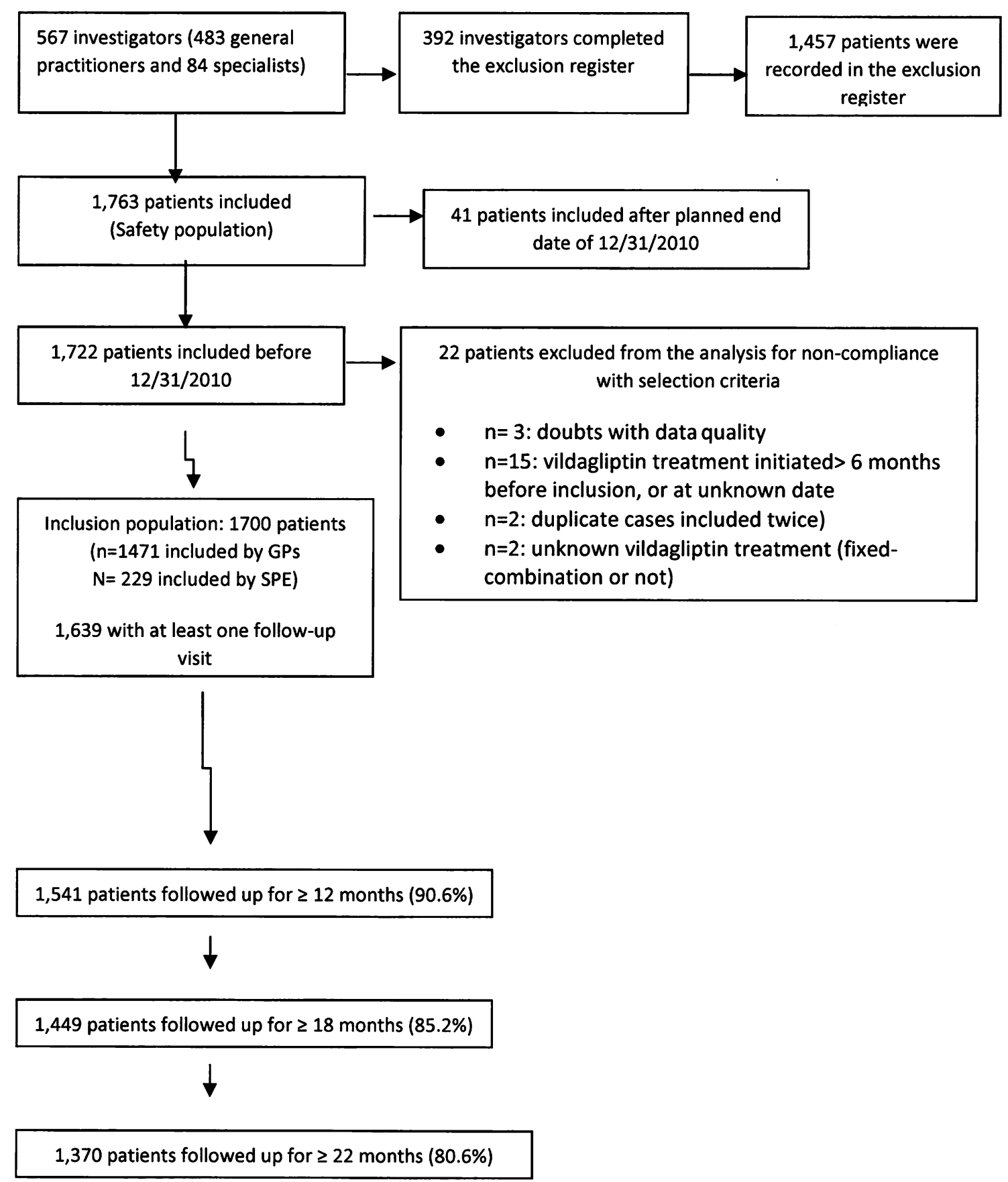

GP, general practitioners; SPE, specialists in endocrinology

Fig. 1 Patients' disposition

included in the study were slightly younger (62.5 years). The reasons for not including patients were: patient's refusal to participate
(41\%), anticipated difficulties for the follow-up (37\%), no time to include the patient at the time of the visit (17\%) and other reasons (5\%). 


\section{Physicians}

No major bias was found in terms of representativeness of the physicians in the different analyses: participating GPs were comparable to all GPs in France with respect to age, area and place of practice, whereas females were under-represented. Patients included by male and female GP were thus compared, and this analysis did not identify any significant difference between these two populations.

\section{Characteristics of the VILDA Population}

Patients' demographic characteristics together with details of their diabetes are presented in Table 1, overall and by physicians (GPs or SPE). Overall, the mean $( \pm \mathrm{SD})$ age of the population was $63.1( \pm 10.9)$ years, with a male predominance $(60.0 \%)$ and a mean body mass index $(\mathrm{BMI})$ of $30.2( \pm 5.6) \mathrm{kg} / \mathrm{m}^{2}$, with about $84 \%$ of overweight and $45 \%$ of obese patients. Mean disease duration was $7.0( \pm 6.5)$ years and mean $\mathrm{HbA}_{1 \mathrm{c}}$ was $7.8 \%( \pm 1.2)$. Most patients had associated cardiovascular risk factors, $70.1 \%$ were treated for hypertension and $66.4 \%$ for dyslipidemia. According to the investigators, $37.0 \%$ of patients complied properly with their recommendations to engage in regular physical activity and $51.0 \%$ with their dietary advices.

A microvascular complication was reported in $1 / 3$ of the population, mainly nephropathy (albuminuria in $12.6 \%$ of patients and renal impairment in $2.8 \%$ ), diabetic retinopathy (4.5\%) and erectile dysfunction (22.8\% of men). A macrovascular complication was described in $14.3 \%$ of patients, predominantly coronary artery disease (12.5\%). Patients included by SPE did not seem to have a more advanced diabetic disease than those included by GPs. Tolerability issues with previous antidiabetic treatment were reported by $15.9 \%$ of patients. A history of symptomatic hypoglycemia was reported by $42.4 \%$ of patients previously treated by insulin secretagogues (sulphonylureas or meglitinides) and that of severe hypoglycemia by $3.7 \%$ of them. The baseline average DTSQs score (before vildagliptin initiation) was $21.5 \pm 5.9$ with GPs and $23.2 \pm 6.0$ with SPE.

\section{Conditions of Use}

Previous antidiabetic therapy was based on monotherapy in about half of the cases, dual therapy in over a third and triple therapy in about $13 \%$. Only $2 \%$ of the patients were drugnaïve. The main reason for vildagliptin initiation was the need to improve glycemic control (in $83.8 \%$ of cases for GPs and $71.6 \%$ for SPE); previous hypoglycemia was a reason for vildagliptin initiation in only $3.0 \%$ of the case for GPs and in $8.3 \%$ of the cases for SPE.

At treatment initiation, vildagliptin was used in monotherapy in $5.4 \%$ of the cases, in dual therapy in $69.4 \%$ of the cases (essentially in combination with metformin in $64 \%$ ), in triple oral therapy or more in $22.8 \%$, and in combination with insulin in $2.5 \%$ of the cases.

In total, $69.4 \%(1,179)$ of the VILDA population received vildagliptin appropriately as dual therapy (in addition to metformin, sulfonylureas or thiazolidinedione), which were the approved indications in 2009. However, 6.4\% of these patients were not in compliance with the SPC, mostly because of sufficient glycemic control prior to the introduction of vildagliptin $\left(\mathrm{HbA}_{1 \mathrm{c}}\right.$ $<6.5 \%)$. Overall, misuse according to the 2009-SPC was, therefore, found in $37.3 \%$ of patients. However, based on the 2013-SPC, which incorporates the new indications for vildagliptin (in monotherapy, triple therapy and combination with insulin), this percentage drops to $12.1 \%$ of patients. 
Table 1 Baseline demographic and disease characteristics

\begin{tabular}{|c|c|c|c|}
\hline & $\begin{array}{l}\text { GP } \\
N=1,471\end{array}$ & $\begin{array}{l}\text { SPE } \\
N=229\end{array}$ & $\begin{array}{l}\text { Total } \\
N=1,700\end{array}$ \\
\hline \multicolumn{4}{|l|}{ Age (years) } \\
\hline Mean \pm SD & $63.4 \pm 10.9$ & $61.1 \pm 10.7$ & $63.1 \pm 10.9$ \\
\hline \multicolumn{4}{|l|}{ Age group (years) } \\
\hline$\geq 75$ & $14.8 \%$ & $8.3 \%$ & $13.9 \%$ \\
\hline \multicolumn{4}{|l|}{ Sex } \\
\hline Male (\%) & $61.0 \%$ & $54.1 \%$ & $60.0 \%$ \\
\hline \multicolumn{4}{|l|}{ Body mass index $\left(\mathrm{kg} / \mathrm{m}^{2}\right)$} \\
\hline Mean \pm SD & $30.2 \pm 5.5$ & $30.5 \pm 6.2$ & $30.2 \pm 5.6$ \\
\hline $\mathrm{BMI} \geq 30 \mathrm{~kg} / \mathrm{m}^{2}(\%)$ & $47.8 \%$ & $42.5 \%$ & $45.4 \%$ \\
\hline \multicolumn{4}{|l|}{$\mathbf{H b A}_{1 \mathrm{c}}(\%)$} \\
\hline Mean \pm SD & $7.8 \pm 1.2$ & $7.5 \pm 1.2$ & $7.8 \pm 1.2$ \\
\hline Median & 7.6 & 7.3 & 7.6 \\
\hline \multicolumn{4}{|l|}{$\mathrm{HbA}_{1 \mathrm{c}}(\%)$ groups } \\
\hline$\leq 7 \%$ & $23.8 \%$ & $38.9 \%$ & $25.8 \%$ \\
\hline$\geq 8 \%$ & $37.0 \%$ & $27.4 \%$ & $35.7 \%$ \\
\hline \multicolumn{4}{|l|}{ Fasting plasma glucose $(\mathrm{mg} / \mathrm{dL})$} \\
\hline Mean \pm SD & $160 \pm 50$ & $150 \pm 40$ & $160 \pm 50$ \\
\hline \multicolumn{4}{|l|}{ Diabetic complications } \\
\hline \multicolumn{4}{|l|}{ Microvascular complication } \\
\hline$\%$ of patients & 32.7 & 34.3 & 32.9 \\
\hline \multicolumn{4}{|l|}{ Macrovascular complication } \\
\hline$\%$ of patients & 14.6 & 12.9 & 14.3 \\
\hline \multicolumn{4}{|l|}{ Duration of T2DM (years) } \\
\hline Mean \pm SD & $6.8 \pm 6.4$ & $8.3 \pm 7.4$ & $7.0 \pm 6.5$ \\
\hline Median (range) & $5.0(0.0-50)$ & $7.0(0.0-43)$ & $5.0(0.0-50)$ \\
\hline$\%$ with history $>5$ years & $47.4 \%$ & $57.0 \%$ & $48.8 \%$ \\
\hline \multicolumn{4}{|l|}{ Previous OAD treatment } \\
\hline Naïve (\%) & 1.8 & 3.0 & 2.0 \\
\hline Monotherapy (\%) & 50.1 & 40.2 & 48.8 \\
\hline Dual therapy (\%) & 35.2 & 37.6 & 35.5 \\
\hline Triple therapy and more \pm insulin (\%) & 12.8 & 19.2 & 13.7 \\
\hline Mean DTSQs score & $21.2 \pm 5.9$ & $23.2 \pm 6.8$ & $21.5 \pm 6.0$ \\
\hline Median (range) & $21.0(6.0-36.0)$ & $24.0(9.0-36.0)$ & $21.0(6.0-36.0)$ \\
\hline History of Hypoglycemia (\%) & 8.6 & 14.7 & 9.4 \\
\hline \multicolumn{4}{|l|}{ Main cardiovascular risk factors } \\
\hline Smokers (current or stopped $<3$ years) & $19.8 \%$ & $13.3 \%$ & $18.9 \%$ \\
\hline Hypertension (treated) & $71.3 \%$ & $62.5 \%$ & $70.1 \%$ \\
\hline Dyslipidemia (treated) & $66.8 \%$ & $63.6 \%$ & $66.4 \%$ \\
\hline \multicolumn{4}{|l|}{ At least 2 cardiovascular risk factors } \\
\hline$\%$ of patients & $71.2 \%$ & $62.4 \%$ & $70.1 \%$ \\
\hline eGFR $($ MDRD $) \geq 60 \mathrm{~mL} / \mathrm{min}$ & $86.5 \%$ & $87.2 \%$ & $86.6 \%$ \\
\hline
\end{tabular}

$\overline{D T S Q}$ Diabetes Treatment Satisfaction Questionnaire, $e G F R$ estimated glomerular filtration rate, $G P$ general practitioner, $H b A_{1 c}$ glycosylated hemoglobin, $M D R D$ Modification of Diet in Renal Disease, $O A D$ oral antidiabetic drug, $S D$ standard deviation, $S P E$ specialists in endocrinology, diabetology and metabolic diseases, T2DM type 2 diabetes mellitus 
Compliance with contraindications or precautions for use of vildagliptin was rather satisfactory with hepatic impairment reported in $2.1 \%$ of patients and heart failure class III and IV in 0.3 and $0.0 \%$ of patients, respectively. Liver function tests were available for $80.3 \%$ of patients, among whom $0.6 \%$ had aspartate transaminase (AST) and/or alanine transaminase (ALT) levels $>3$ times the upper limit of normal. Creatinine results were available in $91 \%$ of patients and $11 \%$ had creatinine clearance $(\mathrm{CrCl})$ below the recommended thresholds in $2009(50 \mathrm{~mL} /$ min for vildagliptin alone and $60 \mathrm{~mL} / \mathrm{min}$ for the metformin-fixed combination). No patient had end-stage renal disease $(<15 \mathrm{~mL} / \mathrm{min})$. The conditions of use of vildagliptin have been amended since, and it can be used (at a dose of $50 \mathrm{mg} /$ day) across all degrees of renal alteration, including in end-stage renal disease.

\section{Treatment Satisfaction and Maintenance} at 2 Years

After vildagliptin initiation, improvement in patient treatment satisfaction was important with an overall DTSQc score of $+9.0( \pm 5.3)$, median 10 (on a scale of -18 to +18 ).

The proportion of patients treated with vildagliptin remained fairly stable over the course of the study with $92.5 \%$ (95\% CI 91.2-93.8\%) of patients still being treated after 1 year and $88.8 \%$ (95\% CI $87.2-90.4 \%)$ of patients still treated at 2 years. The rate of discontinuation over time is presented in Fig. 2.

The most common reasons for treatment discontinuation were insufficient efficacy $(39.7 \%$ of the reasons) and problems of tolerability $(39.1 \%$ of the reasons) both occurring in about $4 \%$ of patients.

\section{Changes in $\mathrm{HbA}_{1 \mathrm{c}}$ and Weight During Treatment with Vildagliptin}

The mean $\mathrm{HbA}_{1 \mathrm{c}}$ decreased sharply in the first months after vildagliptin initiation from a mean baseline of $7.8 \%( \pm 1.2)$ to $7.0 \%( \pm 1.0)$ at the first follow-up visit held approximately at 6 months, and remained stable thereafter, throughout the entire follow-up period (Fig. 3). Due to the complexity of the patients' treatments schemes over a 2-year period of follow-up, it is not possible to present all results according to the detailed treatments received by the patients. However, results were consistent for patients included by GP and by SPE, whether considering vildagliptin alone or the metformin-fixed combination. Importantly, similar results were also seen in the main subpopulation exclusively treated by a dual metformin/vildagliptin therapy $(2 / 3$ of the population) and also in the large subgroup of patients who remained treated with dual therapy only, without any additional treatment $(n=881,75 \%)$ throughout their entire follow-up (data not shown). Finally, further analysis in the sub-population lost to follow-up before study completion (where $\mathrm{HbA}_{1 \mathrm{c}}$ values were only available up to 18 months) also showed consistent results.

The percentage of patients with an $\mathrm{HbA}_{1 \mathrm{c}}$ $<7.0 \%$ increased from $22.1 \%$ initially to $54.0 \%$ at the first visit after vildagliptin initiation, and that proportion remained stable over the course of the study with $57.7 \%$ of patients having an $\mathrm{HbA}_{1 \mathrm{c}}<7.0 \%$ at the last visit after 2 years of vildagliptin treatment.

Body weight showed a slight insignificant downward trend of $2.6 \%$ over the course of the study, from $86.0( \pm 17.7) \mathrm{kg}$ at baseline to 83.8 $( \pm 16.6) \mathrm{kg}$ at 24 months. The proportion of patients whose weight increased by $5 \%$ or more was $8.5 \%$ at 24 months. 


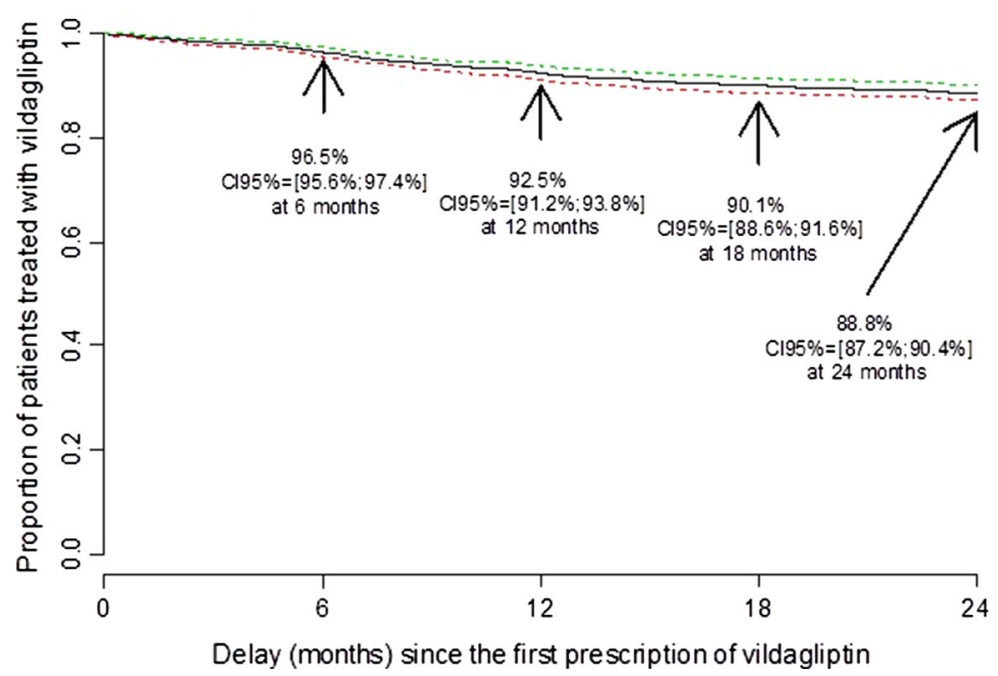

Fig. 2 Vildagliptin maintenance curve over 2 years (solid curve average level, dotted line 95\% confidence interval)

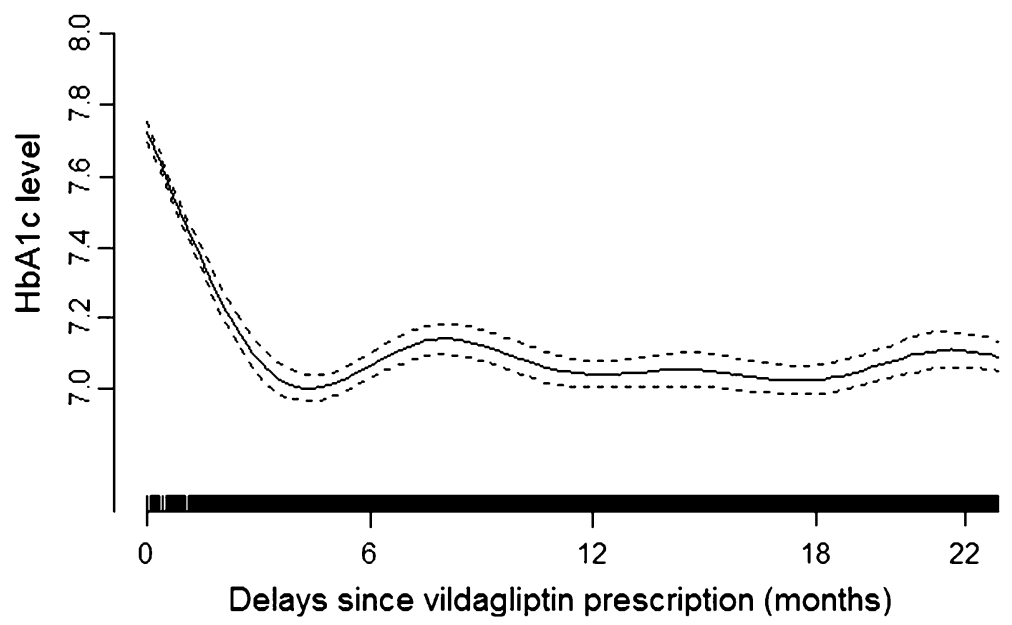

Fig. 3 Changes in $\mathrm{HbA}_{1 \mathrm{c}}$ level over the period of treatment with vildagliptin (solid curve average level, dotted line 95\% confidence interval). $H b A_{1 c}$ glycosylated hemoglobin

\section{Hypoglycemia}

Of the 1,639 patients who had at least one follow-up visit, 8 cases of severe hypoglycemia were reported in 8 patients (i.e., $0.5 \%$ of patients) and 64 episodes of non-severe symptomatic hypoglycemia were reported in 47 patients (i.e., $2.9 \%$ of patients), namely a total of 51 patients $(3.1 \%)$ with 72 episodes of hypoglycemia during the course of treatment. All eight cases of severe hypoglycemia occurred in patients treated concomitantly with insulin and/or sulphonylureas. Among the 64 episodes of non-severe symptomatic hypoglycemia, 38 (59\%) were also related to a concomitant treatment with insulin secretagogues (sulphonylureas and/or meglitinides) and/or with insulin. Overall, taking into account the 1,639 patients who had at least one follow-up visit and who were followed-up on average for 1.73 years on treatment with vildagliptin, the incidence of severe hypoglycemia was 0.24 per 
100 patient years $(95 \%$ CI $0.10-0.46 \%)$ and that of all hypoglycemic episodes was 2.5 per 100 patient years (95\% CI 1.9-3.1\%).

In total, $44.9 \%$ of patients treated with vildagliptin had an $\mathrm{HbA}_{1 \mathrm{c}}$ level $<7.0 \%$, without hypoglycemia and without weight gain ( $>5 \%$ of baseline weight) 6 months after initiation of vildagliptin. This proportion of patients meeting "therapeutic success" increased gradually to $49.7 \%$ at 24 months after initiation of vildagliptin.

\section{Safety}

The average eGFR, transaminases levels and lipid parameters remained essentially stable all along the study. Mean eGFR was $81.9( \pm 22.0)$ $\mathrm{mL} / \mathrm{min}$ at baseline and $83.1( \pm 22.5 \mathrm{~mL} / \mathrm{min})$ at the final visit; mean AST/ALT at baseline was $29.5( \pm 17.6) / 28.5 \quad( \pm 15.9)$ and slightly decreased to a mean of $27.9( \pm 12.2) / 27.5$ $( \pm 12.7)$ at 2 years. Mean low density lipoproteins (LDL)-cholesterol was 1.1 and $1.0 \mathrm{~g} / \mathrm{L}$, respectively (with the \% of patients having $\geq 1.3 \mathrm{~g} / \mathrm{L}$ decreasing from $29.6 \%$ at baseline to $19.4 \%$ at the final visit) and high density lipoproteins (HDL)-cholesterol was stable at $0.5 \mathrm{~g} / \mathrm{L}$ both at baseline and final visit [with a $\%$ of men having $\geq 0.4 \mathrm{~g} / \mathrm{L}$ (72.9\% then $78.7 \%)$ and of women $\geq 0.5 \mathrm{~g} / \mathrm{L}(54.1 \%$ then $51.7 \%)]$.

Safety data were collected on all the 1,763 patients included in the study. Table 2 summarizes the frequency of all AEs, SAEs and events suspected to be related to the vildagliptin treatment. Overall, nearly $20 \%$ of patients reported at least one $\mathrm{AE}$ over 2 years. The most frequent events were functional disorders affecting the gastrointestinal system. Few patients (1.6\%) had at least one event considered serious and related to vildagliptin. No case of pancreatitis was reported. Over the 2-year follow-up period, 15 patients of the 1,763 patients in the safety population $(0.9 \%)$ died of various causes evaluated as not related to vildagliptin by the investigators. They had a mean age of 77 years (range 61-92 years).

\section{DISCUSSION}

The pragmatic VILDA study, commissioned by the French Health Authorities HAS, was designed to thoroughly describe the use of vildagliptin in the management of T2DM under real-life conditions. It brings further insights into the effectiveness of vildagliptin in daily medical practice and complement data on the efficacy/safety profile of the drug gathered from RCTs for registration. No major bias was found that might affect the results of the study in terms of representativeness of patients and prescribers.

To assess the representativeness of the VILDA population, it is of interest to compare the patients with the national sample (2007 "Échantillon National Témoin REprésentatif des personnes Diabétiques" (ENTRED) survey: conducted to monitor the health status of adult diabetic patients from a representative sample of French diabetic patients pharmacologically treated [34]), even if the T2DM patients included in VILDA study were inherently different in that they were seen at the time of treatment intensification. VILDA participants were slightly younger (63 years vs. 66 years in ENTRED), predominantly male (60\% vs. 53\%), and their diabetes was more recent (mean duration from diagnosis of 7 vs. 9 years). The proportion of obese persons was close ( $45 \%$ and $41 \%$, respectively in VILDA and ENTRED), as was that of smokers $(19 \%$ and $16 \%$, respectively) and of patients receiving antihypertensive therapy (70\% and 75\%). 
Table 2 Summary of adverse events

\begin{tabular}{ll}
\hline & $\begin{array}{l}\text { Safety population } \\
(N=1,763)\end{array}$ \\
\hline Number (\%) of patients with & $345(19.6 \%)$ \\
At least one AE & $135(7.7 \%)$ \\
At least one AE suspected to be & \\
related to vildagliptin & $124(7.0 \%)$ \\
At least one SAE & $29(1.6 \%)$ \\
At least one SAE suspected to be & \\
related to vildagliptin & \\
\hline
\end{tabular}

$A E$ adverse events, $S A E$ severe adverse events

Erectile dysfunction was reported for $22.8 \%$ of men in the VILDA study, a fairly comparable rate to the $25 \%$ of ENTRED. Mean $\mathrm{HbA}_{1 \mathrm{c}}$ was higher as expected $(7.8 \%$ vs. $7.1 \%$ overall in ENTRED), since VILDA participants were included at time of treatment intensification and thus frequently had unsatisfactory glucose control.

The mean $\mathrm{HbA}_{1 \mathrm{c}}$ level of $7.8 \%$ at time of treatment intensification in VILDA was remarkably consistent with other real-life studies conducted in France (HYPOCRAS [35]) or in Germany [36], where the mean level before addition of a second agent was identical. While in the large, worldwide EDGE (Effectiveness of Diabetes control with vildaGliptin and vildagliptin/mEtformin) study [31], the overall mean $\mathrm{HbA}_{1 \mathrm{c}}$ recognized as monotherapy failure before the addition of a second OAD, was slightly higher (8.2\%), it was again very similar in Europe. The DIATTITUDE study [37] further looked into the behavior of French GP vis-à-vis intensification of oral antidiabetic agents in T2DM patients, according to their $\mathrm{HbA}_{1 \mathrm{c}}$ level. $41 \%$ of patients had unsatisfactory glucose control $(47 \%, 39 \%$ and $20 \%$, respectively, in monotherapy, dual therapy and $\geq$ triple therapy), with an overall mean $\mathrm{HbA}_{1 \mathrm{c}}$ of $7.5 \%(7.2 \% ; 7.8 \%$ and $9.0 \%$, respectively, in monotherapy, dual therapy and $\geq$ triple therapy). Of these patients, however, only $7 \%$ had their treatment intensified after the visit. There were countless reasons for postponing the pharmacological intensification, many of them legitimate such as reinforcing lifestyle advices first or improvement by comparison with the last measure of glycemic control, but the so-called "therapeutic inertia" was also often in play [37].

The efficacy results observed in real-life in the VILDA study were thoroughly consistent with those obtained during the RCTs. $\mathrm{HbA}_{1 \mathrm{c}}$ decreased from a mean baseline of $7.8 \%$ to a mean of $7.0 \%$ at the first follow-up visit at 6 months and this reduction was then maintained over the 2 years of the VILDA study. Similar results were observed in the subgroup treated exclusively with vildagliptin in dual therapy with metformin and who were prescribed this treatment combination throughout the study without any other drug. In RCTs, patients were recruited worldwide and were on average slightly younger, tended to be more obese, and often presented with higher $\mathrm{HbA}_{1 \mathrm{c}}[26,38]$, with some exceptions [19]. In the main registration study in add-on to metformin, a reduction of $-0.9 \%$ was seen from a mean baseline of $8.4 \%$ [10], while in another trial in add-on to metformin starting from a much lower baseline of $7.3 \%$, mean $\mathrm{HbA}_{1 \mathrm{c}}$ decreased to $6.8 \%$ by weeks 12 with vildagliptin and remained essentially stable thereafter with a mean $\mathrm{HbA}_{1 \mathrm{c}}$ of $6.75 \%$ at week 52. This illustrates the well known and typical trend of greater $\mathrm{HbA}_{1 \mathrm{c}}$ reductions seen from higher baseline levels [39]. A pooled analysis of phase 3 studies also showed mean changes in $\mathrm{HbA}_{1 \mathrm{c}}$ with vildagliptin of $-0.9 \%$ from a mean baseline of $8.4 \%$ in add-on to 
metformin [26]. Further analysis in add-on to metformin showed that efficacy was about the same regardless of BMI, disease duration or duration of metformin use, with significant drops in $\mathrm{HbA}_{1 \mathrm{c}}$ of approximately $-0.7 \%$ from a mean baseline of $7.7 \%$ [15]. This is actually similar to the results in VILDA from a similar baseline, in the overall population and in the main subgroup treated in dual therapy with metformin. In addition, the results of the VILDA study highlight the durability of effects over 2 years, which was also seen in RCTs [20, 40].

Hypoglycemia is one of the main limitations for glucose-lowering therapy and also a key factor underlying clinical inertia [41]. Low hypoglycemic risk is an essential feature of the DPP4-I class of drugs and has been largely documented in clinical trials with vildagliptin [11], stemming from a strong mechanistic rationale [42]. In a recent German database study, DPP4-I use was associated with a fivefold reduced frequency of patients with hypoglycemia compared to sulphonylureas (SU) [43]. In the French HYPOCRAS study [35], the proportion of T2DM patients (of mean age 71) reporting hypoglycemia over 6 months was $6.4 \%$ with a DPP4-I vs. $26 \%$ with SU or glinides, and that of severe hypoglycemic events was, respectively, $0.1 \%$ vs. $3.2 \% \quad(p<0.001)$. In keeping with these data, the improvement in glycemic control in the VILDA study was not associated with an increased risk of hypoglycemia, the incidence of which remained very low over 2 years. Moreover, severe hypoglycemic episodes were observed exclusively in combination with insulinsecreting treatment (SU and/or glinides) and/ or with insulin, and symptomatic episodes were reported primarily in patients concomitantly treated with SU and/or glinide and/or insulin.
Among patients previously treated with SU and/or glinides before starting vildagliptin, the proportion of those reporting a history of severe hypoglycemia was $3.7 \%$. This figure is fairly comparable to that found in the literature: in the HYPOCRAS study, $3.2 \%$ of patients treated with an SU or glinide experienced an episode of severe hypoglycemia over the 6-month study period [35]. In the ENTRED study, 5\% of subjects' $\geq 65$ years treated with SU reported at least one episode of severe hypoglycemia over a period of 1 year [44]. Severe hypoglycemia has been associated with a higher risk of cardiovascular disease, and this association did not seem to be solely explained by comorbid severe illness [45]. Research also demonstrated the impact of hypoglycemia, as well as fear of hypoglycemia, on quality of life, related outcomes and healthcare utilization of people with T2DM [46, 47]. In a recent prospective observational study carried out as an addendum to a mandatory study of the Italian Medicine Agency (AIFA), the fixed combination vildagliptin/metformin over 1 year was shown to improve patient satisfaction, quality of life (DTSQ) and work productivity measured as Work Productivity and Activity Impairment (WPAI) scores [48].

An important dimension that needs to be taken into account is the adherence to prescribed medications. Discontinuation of antidiabetic therapy results in substantial costs for the healthcare system and appears to be frequently found in primary care patients. The ENTRED survey examined medication adherence using a 6-item self-administered questionnaire in 3,637 persons with T2DM: $61 \%$ of patients reported medium to poor adherence [49]. This level of medication adherence was unexpectedly low in France, a country with a high level of access to healthcare. In a database study conducted in 
1,201 general practices in Germany [43], therapy persistence with DPP4-I (19,184 users) and SU (31,110 users) was compared. Two years after index date, DDP4-I was associated with a lower risk of discontinuation compared to SU (39\% vs. 49\%) [adjusted hazard ratio (HR) 0.74; 95\% CI 0.71-0.76] [43]. In view of these data, the treatment maintenance rate in the VILDA study at 2 years was very satisfactory at $88.8 \%$ (95\% CI 87.2-90.4\%) in line with the improved satisfaction reported with treatment $(+9$ at the DTSQc), and the good and well-maintained efficacy with few tolerability issues (4\% of patients discontinued treatment for adverse events over the entire study period) and low hypoglycemia risk.

This study is also consistent with other reallife studies worldwide. The largest-scale study was EDGE, a 1-year, prospective study of more than 45,000 patients with T2DM not reaching glycemic targets with monotherapy, conducted in 27 countries from Europe, Central and Latin America, Asia and Middle East [31]. Physicians could add vildagliptin (vildagliptin cohort) or any other OAD (pooled comparator cohort). The primary end-point (proportions of patients with $\mathrm{HbA}_{1 \mathrm{c}}$ decrease $>0.3 \%$, without hypoglycemia, weight gain, peripheral edema or gastrointestinal side-effects) was attained more frequently in the vildagliptin vs. the comparator cohort, with an adjusted odds ratio of 1.49 (95\% CI 1.42, 1.55; $p<0.001)$. In this setting, vildagliptin as second $\mathrm{OAD}$ lowered $\mathrm{HbA}_{1 \mathrm{c}}$ by about $1 \%$ from a mean baseline of 8.2\%. Other DPP4-I have been studied as well in real-life conditions, such as sitagliptin in the SUGAR study [50], a large Belgian prospective observational study of shorter duration.

This study has usual strengths and limitations. Physician participation was decided on a voluntary basis, which constitutes a classic potential selection bias in this type of study. However, the investigators were representative of all French GP and SPE across several characteristics, with the exception of a slightly higher proportion of men among the VILDA investigators. Another potential selection bias comes from the fact that the treating physician chooses which patient was included into the study. However, comparison of the patients included with patients from the non-inclusion registry did not reveal any bias that might affect the results of this study. Thus, these data can be considered as reliable and nicely representative of current care delivery to diabetic patients treated with vildagliptin in France. Some patients were lost during the follow-up. However, the rate of $80.6 \%$ of patients followed over 2 years is satisfactory, in line with the authors' statistical hypothesis, and compares well with other studies of identical design, such as AVANCE where this rate was $62.4 \%$ [51]. Finally, the quality of data collection in observational studies is always questioning. The quality of the data collection was assessed during the survey auditing collected files in a 5\% random sample of all enrolled patients. Audit results were positive not showing serious irregularities or anomalies.

\section{CONCLUSION}

The present study provides important information for management of T2DM in daily practice, as it emphasizes the effectiveness of vildagliptin treatment, with a low risk of hypoglycemia and fairly good persistence at mid-term, in a large population of patients in the real-world environment. It confirms the results obtained under controlled conditions in selected patients from RCTs. 


\section{ACKNOWLEDGMENTS}

Sponsorship and article processing charges for this study were funded by Novartis Pharma SAS (Rueil Malmaison, France).

All named authors meet the ICMJE criteria for authorship for this manuscript, had full access to all of the data in this study, take responsibility for the accuracy of the data analysis and integrity of the work as a whole, and have given final approval for the version to be published.

The authors gratefully acknowledge the patients and investigators at the participating sites, Rémy Soulhol for his work on study coordination, Serge Menn for his work on safety data and Stéphane Quéré for statistical assistance, and the logistics team at CEMKAEVAL (Bourg-La-Reine, France).

Conflict of interest. D. Simon has served on speaker's bureaus of Sanofi-Aventis and Lilly France, on advisory panels for Astra-Zeneca, Boehringer-Ingelheim, Bristol Myers Squibb, Jannsen and Novartis and has participated as an investigator in studies conducted by Lilly France, Novartis and Novo-Nordisk.

B. Detournay is a consultant for CEMKAEVAL, a company providing consultancy services for most private companies and public institutions involved in health care in France.

S. Bouée is a consultant for CEMKA-EVAL, a company providing consultancy services for most private companies and public institutions involved in health care in France.

E. Eschwege has been member of advisory boards and had speaker engagements for NovoNordisk, Novartis and Roche, and served as consultant for the Institut National de Veille Sanitaire, HAS/Commission de la transparence/ groupe d'intérêt de santé publique.
J. Bringer has received fees for consultancy, advisory boards, speaking, travel or accommodation from Novartis Pharma, Lilly, Novo-Nordisk, MSD and Sanofi.

C. Attali has received fees for scientific committee and advisory boards for BoehringerIngelheim, Novartis and Astra-Zeneca.

S. Dejager is an employee of Novartis Pharma.

Compliance with ethics. All procedures followed were in accordance with the ethical standards of the French Order of Physicians and Good Practices for Epidemiological Studies and with the Helsinki Declaration of 1975, as revised in 2000 and 2008. Candidates for inclusion were provided with full written information about the study. All data processing was carried out in compliance with French Information Technology and Privacy Law.

Funding. This study was funded by Novartis Pharma SAS (Rueil Malmaison, France).

Open Access. This article is distributed under the terms of the Creative Commons Attribution Noncommercial License which permits any noncommercial use, distribution, and reproduction in any medium, provided the original author(s) and the source are credited.

\section{REFERENCES}

1. $\mathrm{Hu}$ FB. Globalization of diabetes: the role of diet, lifestyle, and genes. Diabetes Care. 2011;34: 1249-57.

2. Online version of IDF Diabetes Atlas. International Diabetes Federation 2013. www.idf.org/ diabetesatlas. Last Accessed Feb 2014.

3. Hill JO, Galloway JM, Goley A, Marrero DG, Minners R, Montgomery B, Peterson GE, Ratner RE, Sanchez E, Aroda VR. Scientific statement: socioecological determinants of prediabetes and type 2 diabetes. Diabetes Care. 2013;36:2430-9. 
4. Tamayo T, Rosenbauer J. Wild SH, Spijkerman AM, Baan C, Forouhi NG, Herder C, Rathmann W: Diabetes in Europe: An update for 2013 for the IDF Diabetes Atlas. Diabetes Res Clin Pract. 2014;103: 206-17.

5. Bonaldi C, Vernay M, Roudier C, Salanave B, Oleko A, Malon A, Castetbon K, Fagot-Campagna A. A first national prevalence estimate of diagnosed and undiagnosed diabetes in France in 18- to 74-yearold individuals: the French Nutrition and Health Survey 2006/2007. Diabet Med. 2011;28:583-9.

6. Zhang P, Zhang X, Brown J, Vistisen D, Sicree R, Shaw J, Nichols G. Global healthcare expenditure on diabetes for 2010 and 2030. Diabetes Res Clin Pract. 2010;87:293-301.

7. Inzucchi SE, Bergenstal RM, Buse JB, Diamant $\mathrm{M}$, Ferrannini E, Nauck M, Peters AL, Tsapas A, Wender R, Matthews DR. Management of hyperglycemia in type 2 diabetes: a patient-centered approach: position statement of the American Diabetes Association (ADA) and the European Association for the Study of Diabetes (EASD). Diabetes Care. 2012;35:1364-79.

8. Haute Autorité de Santé. Stratégie médicamenteuse du contrôle glycémique du diabète de type 2 . Recommandations de bonne pratique. HAS, pp 0-25. http://www.hassante.fr/portail/jcms/c_ $1022476 / \mathrm{fr} /$ strategie-medicamenteuse-du-controleglycemique-du-diabete-de-type-2. Accessed Feb 2014.

9. Ahren B, Schweizer A, Dejager S, Villhauer EB, Dunning BE, Foley JE. Mechanisms of action of the dipeptidyl peptidase-4 inhibitor vildagliptin in humans. Diabetes Obes Metab. 2011;13:775-83.

10. Bosi E, Camisasca RP, Collober C, Rochotte E, Garber AJ. Effects of vildagliptin on glucose control over 24 weeks in patients with type 2 diabetes inadequately controlled with metformin. Diabetes Care. 2007;30:890-5.

11. Dejager S, Schweizer A. Minimizing the risk of hypoglycemia with vildagliptin: clinical experience, mechanistic basis, and importance in type 2 diabetes management. Diabetes Ther. 2011;2:51-66.

12. Dejager S, Razac S, Foley JE, Schweizer A. Vildagliptin in drug-naive patients with type 2 diabetes: a 24-week, double-blind, randomized, placebo-controlled, multiple-dose study. Horm Metab Res. 2007;39:218-23.

13. Pi-Sunyer FX, Schweizer A, Mills D, Dejager S. Efficacy and tolerability of vildagliptin monotherapy in drug-naive patients with type 2 diabetes. Diabetes Res Clin Pract. 2007;76:132-8.

14. Fonseca V, Baron M, Shao Q, Dejager S. Sustained efficacy and reduced hypoglycemia during one year of treatment with vildagliptin added to insulin in patients with type 2 diabetes mellitus. Horm Metab Res. 2008;40:427-30.

15. Schweizer A, Dejager S, Foley JE. Impact of insulin resistance, body mass index, disease duration, and duration of metformin use on the efficacy of vildagliptin. Diabetes Ther. 2012;3:8.

16. Fonseca V, Schweizer A, Albrecht D, Baron MA, Chang I, Dejager S. Addition of vildagliptin to insulin improves glycaemic control in type 2 diabetes. Diabetologia. 2007;50:1148-55.

17. Kothny W, Foley J, Kozlovski P, Shao Q, Gallwitz B, Lukashevich V. Improved glycaemic control with vildagliptin added to insulin, with or without metformin, in patients with type 2 diabetes mellitus. Diabetes Obes Metab. 2013;15:252-7.

18. Dejager S, Schweizer A, Foley JE. Evidence to support the use of vildagliptin monotherapy in the treatment of type 2 diabetes mellitus. Vasc Health Risk Manag. 2012;8:339-48.

19. Ferrannini E, Fonseca V, Zinman B, Matthews D, Ahren B, Byiers S, Shao Q, Dejager S. Fifty-two-week efficacy and safety of vildagliptin vs. glimepiride in patients with type 2 diabetes mellitus inadequately controlled on metformin monotherapy. Diabetes Obes Metab. 2009;11:157-66.

20. Matthews DR, Dejager S, Ahren B, Fonseca V, Ferrannini E, Couturier A, Foley JE, Zinman B. Vildagliptin add-on to metformin produces similar efficacy and reduced hypoglycaemic risk compared with glimepiride, with no weight gain: results from a 2-year study. Diabetes Obes Metab. 2010;12:780-9.

21. Lukashevich V, Prato SD, Araga M, Kothny W. Efficacy and safety of vildagliptin in patients with type 2 diabetes mellitus inadequately controlled with dual combination of metformin and sulphonylurea. Diabetes Obes Metab. 2013.

22. Charbonnel B, Schweizer A, Dejager S. Combination therapy with DPP-4 inhibitors and insulin in patients with type 2 diabetes mellitus: what is the evidence? Hosp Pract. 1995;2013(41):93-107.

23. Bourdel-Marchasson I, Schweizer A, Dejager S. Incretin therapies in the management of elderly patients with type 2 diabetes mellitus. Hosp Pract. 1995;2011(39):7-21.

24. Halimi S, Raccah D, Schweizer A, Dejager S. Role of vildagliptin in managing type 2 diabetes mellitus in the elderly. Curr Med Res Opin. 2010;26:1647-56.

25. Pratley RE, Rosenstock J, Pi-Sunyer FX, Banerji MA, Schweizer A, Couturier A, Dejager S. Management of type 2 diabetes in treatment-naive elderly 
patients: benefits and risks of vildagliptin monotherapy. Diabetes Care. 2007;30:3017-22.

26. Schweizer A, Dejager S, Foley JE, Shao Q, Kothny W. Clinical experience with vildagliptin in the management of type 2 diabetes in a patient population $>/=75$ years: a pooled analysis from a database of clinical trials. Diabetes Obes Metab. 2011;13:55-64.

27. Dejager S, Schweizer A. Incretin therapies in the management of patients with type 2 diabetes mellitus and renal impairment. Hosp Pract. 1995;2012(40):7-21.

28. Schweizer A, Dejager S. Experience with Vildagliptin in Patients $>/=75$ Years with Type 2 Diabetes and Moderate or Severe Renal Impairment. Diabetes Ther. 2013;4:257-67.

29. Lukashevich V, Schweizer A, Foley JE, Dickinson S, Groop PH, Kothny W. Efficacy of vildagliptin in combination with insulin in patients with type 2 diabetes and severe renal impairment. Vasc Health Risk Manag. 2013;9:21-8.

30. Schweizer A, Foley JE, Kothny W, Ahren B. Clinical evidence and mechanistic basis for vildagliptin's effect in combination with insulin. Vasc Health Risk Manag. 2013;9:57-64.

31. Mathieu C. Barnett AH, Brath H, Conget I, de Castro JJ, Goke R, Marquez RE, Nilsson PM, Pagkalos E, Penfornis A, Schaper NC, Wangnoo SK, Kothny W, Bader G: Effectiveness and tolerability of second-line therapy with vildagliptin vs. other oral agents in type 2 diabetes: a real-life worldwide observational study (EDGE). Int J Clin Pract. 2013;67:947-56.

32. Bradley C. The Diabetes Treatment Satisfaction Questionnaire (DTSQ): change version for use alongside status version provides appropriate solution where ceiling effects occur. Diabetes Care. 1999;22(3):530-2.

33. Rigalleau V, Lasseur C, Perlemoine C, et al. Estimation of glomerular filtration rate in diabetic subjects: Cockcroft formula or modification of Diet in Renal Disease study equation? Diabetes Care. 2005;28(4):838-43.

34. Druet C, Bourdel-Marchasson I, Weill A, Eschwege E, Penfornis A, Fosse S, Fournier C, Chantry M, Attali C, Lecomte P, Simon D, Poutignat N, Gautier A, Risse M, Fagot-Campagna A. Type 2 diabetes in France: epidemiology, trends of medical care, social and economic burden. Presse Med. 2013;42:830-8.

35. Penfornis A, Bourdel-Marchasson I, Quere S, Dejager S. Real-life comparison of DPP4-inhibitors with conventional oral antidiabetics as add-on therapy to metformin in elderly patients with type 2 diabetes: the HYPOCRAS study. Diabetes Metab. 2012;38:550-7.

36. Goke R, Gruenberger JB, Bader G, Dworak M. Reallife efficacy and safety of vildagliptin compared with sulfonylureas as add-on to metformin in patients with type 2 diabetes mellitus in Germany. Curr Med Res Opin. 2014.

37. Halimi S, Balkau B, Attali C, Detournay B, Amelineau E, Blickle JF. Therapeutic management of orally treated type 2 diabetic patients, by French general practitioners in 2010: the DIAttitude Study. Diabetes Metab. 2012;38(Suppl 3):S36-46.

38. Schweizer A, Couturier A, Foley JE, Dejager S. Comparison between vildagliptin and metformin to sustain reductions in $\mathrm{HbA}(1 \mathrm{c})$ over 1 year in drug-naive patients with Type 2 diabetes. Diabet Med. 2007;24:955-61.

39. DeFronzo RA, Stonehouse AH, Han J, Wintle ME. Relationship of baseline HbA1c and efficacy of current glucose-lowering therapies: a metaanalysis of randomized clinical trials. Diabet Med. 2010;27:309-17.

40. Goke B, Hershon K, Kerr D, Calle PA, Schweizer A, Foley J, Shao Q, Dejager S. Efficacy and safety of vildagliptin monotherapy during 2-year treatment of drug-naive patients with type 2 diabetes: comparison with metformin. Horm Metab Res. 2008;40:892-5.

41. Ahren B. Avoiding hypoglycemia: a key to success for glucose-lowering therapy in type 2 diabetes. Vasc Health Risk Manag. 2013;9:155-63.

42. Ahren B, Schweizer A, Dejager S, Dunning BE, Nilsson PM, Persson M, Foley JE. Vildagliptin enhances islet responsiveness to both hyper- and hypoglycemia in patients with type 2 diabetes. J Clin Endocrinol Metab. 2009;94:1236-43.

43. Rathmann W, Kostev K, Gruenberger JB, Dworak M, Bader G, Giani G. Treatment persistence, hypoglycaemia and clinical outcomes in type 2 diabetes patients with dipeptidyl peptidase-4 inhibitors and sulphonylureas: a primary care database analysis. Diabetes Obes Metab. 2013;15:55-61.

44. Pornet C, Bourdel-Marchasson I, Lecomte P, Eschwege E, Romon I, Fosse S, Assogba F, Roudier C, Fagot-Campagna A. Trends in the quality of care for elderly people with type 2 diabetes: the need for improvements in safety and quality (the 2001 and 2007 ENTRED Surveys). Diabetes Metab. 2011;37: 152-61.

45. Goto A, Arah OA, Goto M, Terauchi Y, Noda M. Severe hypoglycaemia and cardiovascular disease: 
systematic review and meta-analysis with bias analysis. BMJ. 2013;347:f4533.

46. Barendse S, Singh H, Frier BM, Speight J. The impact of hypoglycaemia on quality of life and related patient-reported outcomes in Type 2 diabetes: a narrative review. Diabet Med. 2012;29:293-302.

47. Williams SA, Shi L, Brenneman SK, Johnson JC, Wegner JC, Fonseca V. The burden of hypoglycemia on healthcare utilization, costs, and quality of life among type 2 diabetes mellitus patients. J Diabetes Complications. 2012;26:399-406.

48. Genovese S, Tedeschi D. Effects of vildagliptin/ metformin therapy on patient-reported outcomes: work productivity, patient satisfaction, and resource utilization. Adv Ther. 2013;30:152-64.
49. Tiv M, Viel JF, Mauny F, Eschwege E, Weill A, Fournier C, Fagot-Campagna A, Penfornis A. Medication adherence in type 2 diabetes: the ENTRED study 2007, a French Population-Based Study. PLoS ONE. 2012;7:e32412.

50. Scheen AJ, Van Gaal LF. Sugar: results of a Belgian observational study on the use of sitagliptin in patients with type 2 diabetes. Rev Med Liege. 2010;65:127-32.

51. Halimi S, Aubert JP, Fontbonne A, Guillausseau PJ, Nachit F, Bouee S, Detournay B. A real-life study of the use, effectiveness and tolerability of rosiglitazone in France: the AVANCE study. Diabetes Metab. 2012;38: 343-51. 